Andarge Zelalem, ${ }^{1 *}$ Kebede Abegaz, ${ }^{2}$ Ameha Kebede, ${ }^{1}$ Yitagele Terefe, ${ }^{3}$ Carla L. Schwan, ${ }^{4}$ and Jessie L. Vipham ${ }^{4}$

${ }^{1}$ School of Biological Sciences \& Biotechnology, Haramaya University, P.O. Box 138, Dire Dawa, Ethiopia 2Dept. of Food Science \& Technology, College of Agriculture, Hawassa University, Hawassa, Ethiopia

${ }^{3}$ College of Veterinary Medicine, P.O. Box 138, Haramaya University, Dire Dawa, Ethiopia

${ }^{4}$ Dept. of Animal Sciences and Industry, Kansas State University, 247 Weber Hall, Manhattan, KS 66506, USA
PEER-REVIEWED ARTICLE

Food Protection Trends, Vol. 41, No. 5, p. 501-509 Copyright $^{\oplus}$ 2021, International Association for Food Protection 2900 100th Street, Suite 309, Des Moines, IA 50322-3855, USA

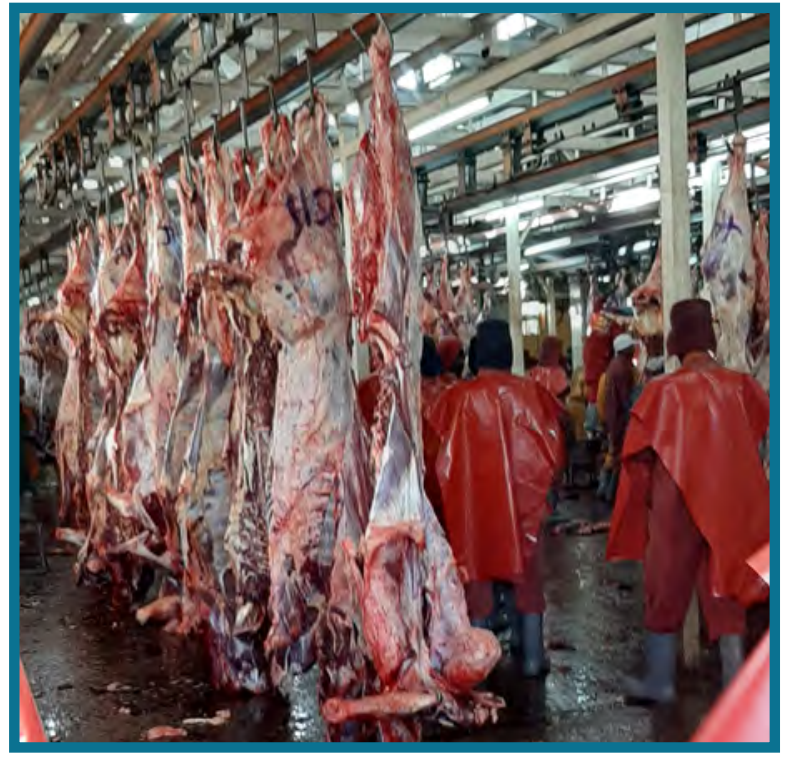

\title{
Food Safety Knowledge, Attitudes, and Hygienic Practices of Abattoir Workers in Ethiopia: A Cross-Sectional Study
}

\section{ABSTRACT}

This cross-sectional study assessed food safety knowledge, attitudes, and hygienic practices of workers in three abattoir facilities in Ethiopia. A food safety questionnaire was administered to 422 respondents. Results showed that $\mathbf{6 3 . 3} \%$ of respondents demonstrated poor food safety knowledge, with a mean score of $47.21 \pm 17.19$. Nearly, $46 \%$ of respondents demonstrated good attitudes, with a mean score of $62.24 \pm 9.50$. Approximately $61 \%$ of respondents were classified as having good practices, with a mean score of $51.68 \pm 8.18$. A significant, positive correlation was observed between knowledge and practices $\left(r_{s}=0.569, P<0.0001\right)$, knowledge and attitudes $\left(r_{s}\right.$ $=0.735, P<0.0001)$, and practices and attitudes $\left(r_{s}=\right.$ $0.518, P<0.0001$ ). Logistic regression analysis showed that the education level of respondents was significantly associated with food safety knowledge $(P<0.0001)$. Primary school education $(P=0.013)$ and informal education $[P<0.0001$ ) were factors associated with food safety attitudes. In addition, poor knowledge $(P=0.01)$, less than 2 years of work experience $(P=0.023)$, and contract employment status $[P<0.0001)$ were significantly associated with respondents' food safety practices. This study provides evidence that educational-based intervention is needed for abattoir workers to improve meat safety.

\section{INTRODUCTION}

According to the World Health Organization, biological hazards are responsible for $70 \%$ of the global burden of foodborne diseases (24). Worldwide studies have shown that animal-source foods are the most common causes of foodborne diseases $(23,25)$. For example, studies conducted in the Netherlands and China identified animal-source foods as the most common cause of foodborne diseases $(12,33)$. In the United States, it has been reported that meat contributes to $23.2 \%$ of the total number of foodborne illnesses caused by bacterial agents compared with other-source foods, although sources vary (32). In 2015, the European Union identified meat as a major source of Salmonella enterica, Campylobacter, and Shiga toxin-producing Escherichia coli (STEC), all of which are known for causing foodborne disease (18). 
Although comprehensive data on the burden of foodborne disease is limited in Ethiopia, studies in the country have shown that S. enterica, E. coli O157:H7, Campylobacter spp., Listeria monocytogenes, and Staphylococcus aureus are prevalent in animal-source foods $(10,17,21,22,28,29)$. Adequate abattoir facilities and good hygiene standards are major gaps in the country, posing multiple food safety challenges (cross-contamination, pathogen harborage within facilities, etc.) (22).

Beef is the most widely consumed meat in Ethiopia and is commonly supplied by butcheries, restaurants, pubs, hotels, and cafeterias (36). Meat safety is an important concern, because Ethiopians have a deep cultural tradition of consuming raw or undercooked meat (e.g., "Kitfo" and "Kurt") (11). There is a significant lack of food safety oversight within urban and rural abattoirs, and general infrastructure is poor (e.g., no electricity, water, chiller, refrigerated truck, or hanging rails). In addition, bacterial contamination during the slaughtering process can originate from multiple sources but is commonly associated with poor sanitation of equipment and food-contact surfaces, as well as poor personnel hygiene $(16,31,38)$. Collectively, these factors might increase the risk of foodborne diseases associated with raw meat consumption in Ethiopia.

Previous studies in Ethiopia examining food handler's knowledge, attitudes, and practices (KAP) as it relates to food safety have mainly focused on public food establishments, such as hotels, restaurants, cafeterias, butcheries, and juice houses $(7,13,34,40)$. The few studies that have evaluated the KAP of abattoir workers have been conducted in the cities of Mekelle and Jigjiga, which are two regions with significant cultural and agroecological differences compared with the rest of Ethiopia $(22,37)$. To our knowledge, no published studies have evaluated KAP of abattoir workers in Addis Ababa, Hawassa, and Dire Dawa, Ethiopia. Therefore, this study aimed to assess abattoir workers' food safety KAP and its associated factors.

\section{MATERIALS AND METHODS}

\section{Description of the study area}

The Addis Ababa Abattoirs enterprise is the largest facility situated in the capital city of Ethiopia, Addis Ababa. The Hawassa municipal abattoir is geographically situated in Hawassa City, south Ethiopia, and the Dire Dawa municipal abattoir is located in the eastern region of the country, Dire Dawa City, near Port Djibouti. According to information from abattoir offices, the average numbers of animals slaughtered per day at these Addis Ababa, Hawassa, and Dire Dawa abattoir facilities were 702, 150 , and 120 , respectively. These abattoir facilities were purposively selected because of their slaughtering capacity and location in different regions of Ethiopia with significant agroecological and cultural differences.

\section{Study design and questionnaire administration}

Institutional-based cross-sectional study design was carried out between March 2019 and January 2020. The study participants were abattoir workers involved in meat inspection, supervision, slaughtering, cleaning, and transportation. The sample size was determined using the single population proportion formula, considering the following assumptions: $50 \%$ of workers with good knowledge, attitudes, and hygiene practices toward food safety, a $95 \%$ confidence level, and a 5\% margin of error. The required sample size for this study was 384; after adding $10 \%$ for the nonresponse rate, the final sample size was 422 . Finally, the sample size from each abattoir was proportionally allocated as Addis Ababa (246), Dire Dawa (92), and Hawassa (84). Systematic random sampling based on an employee's identification card was used to select participants for the study.

The data were collected using a structured questionnaire that was adapted from different food safety studies $(9,20$, $26,37)$. The questionnaires were categorized into four parts, namely, (1) sociodemographic characteristics, (2) food safety knowledge, (3) food safety attitudes, and (4) hygienic practices of abattoir workers. In the sociodemographic characteristics section, the education level of respondents was categorized as informal (participants who didn't have formal education and never attended school but they knowledge gained through experience), primary school, and high school education and above.

In the knowledge section of the questionnaire, 27 questions assessed the workers' understanding of hygiene practices, contamination sources, potential foodborne illness outcomes, and temperature control. Each question consisted of three possible answers: "Yes," "No," and "I don't know." The scoring criterion for the answers was one point for each correct answer and zero points for each incorrect answer and/or "I don't know." Finally, the total points per respondent, per section, were calculated as a percentage score based on the total points possible. Final percentage scores of respondents were categorized as poor knowledge $(\leq 50 \%)$ and good knowledge (>50\%) (2).

For assessing food safety attitudes, 20 statements were given, and respondents were asked to indicate their level of agreement to the statements. Responses were rated on a 5-point rating scale, ranging from 1 point (strongly disagree) to 5 points (strongly agree) for the correct statement and 5 points (strongly disagree) to 1 point (strongly agree) for the incorrect statement. The corresponding scores assigned to responses ranged between 20 and 100. The scores of each respondent were added together and categorized as poor attitudes ( $\leq 60 \%$ score) and good attitudes ( $>60 \%$ score) with slight modification (2).

For assessing the hygiene practices of respondents, 13 questions were provided with 5-point rating scale: never, rarely, sometimes, often, and always. The responses ratings ranged 
from 1 point (never) to 5 points (always). However, for items of incorrect practices, the score was assigned to responses ranged from 5 points (never) to 1 point (always). Total scores of respondents were computed as a percentage based on total points possible. The respondents' score was categorized as poor practices $(\leq 50 \%)$ and good practices $(>50 \%)(2)$.

\section{Quality control}

The content of the questionnaire was peer reviewed by food safety experts. The items were edited, reordered, and modified to improve clarity. The revised questionnaire was then pretested on 5\% of respondents in an abattoir facility outside the research area. The internal consistency of the KAP questionnaire of the pilot study was acceptable (Cronbach's alpha $=0.88)$. The questionnaire was created in English but then translated and administered in Amharic. The consent of the respondents was obtained before administration of the questionnaire. All questionnaires were followed by a face-to-face interview. Six interviewers were trained to conduct assessments. The interviewers were B.Sc. or higher degrees with an educational background in food and other health sciences. To administer the questionnaire, the questions were read aloud, with respondents given enough time ( 15 to $20 \mathrm{~min}$ ) to respond for the questionnaire.

\section{Ethical consideration and approval}

This project was reviewed and approved by Institutional Review Board of Hawassa University, College of Health and Medical Sciences (Ref. IRB/058/11) (provided as supplemental material).

\section{TABLE 1. Demographic characteristics of respondents $(n=422$ )}

Demographic variable

Participants, $n(\%)$

\begin{tabular}{|c|c|}
\hline \multicolumn{2}{|l|}{ Sex } \\
\hline Male & $398(94.3)$ \\
\hline Female & $24(5.7)$ \\
\hline \multicolumn{2}{|l|}{ Age } \\
\hline$\leq 35$ years & $279(66.1)$ \\
\hline$>36$ years & $143(33.9)$ \\
\hline \multicolumn{2}{|l|}{ Educational level } \\
\hline High school education and above & $184(43.6)$ \\
\hline Primary school education & $207(49.1)$ \\
\hline Informal education & $31(7.3)$ \\
\hline \multicolumn{2}{|l|}{ Job responsibility } \\
\hline Cleaner & $57(13.5)$ \\
\hline Slaughterer & $246(58.3)$ \\
\hline Meat distributor & $78(18.5)$ \\
\hline Supervisor & $31(7.3)$ \\
\hline Meat inspector & $10(2.4)$ \\
\hline \multicolumn{2}{|l|}{ Work experience } \\
\hline$<2$ years & $41(9.7)$ \\
\hline$\geq 2$ years & $381(90.3)$ \\
\hline \multicolumn{2}{|l|}{ Employment status } \\
\hline Permanent & $239(56.6)$ \\
\hline Contract & $62(14.7)$ \\
\hline Daily & $121(28.7)$ \\
\hline \multicolumn{2}{|l|}{ Food safety training } \\
\hline Yes & $230(54.5)$ \\
\hline No & $192(45.5)$ \\
\hline
\end{tabular}




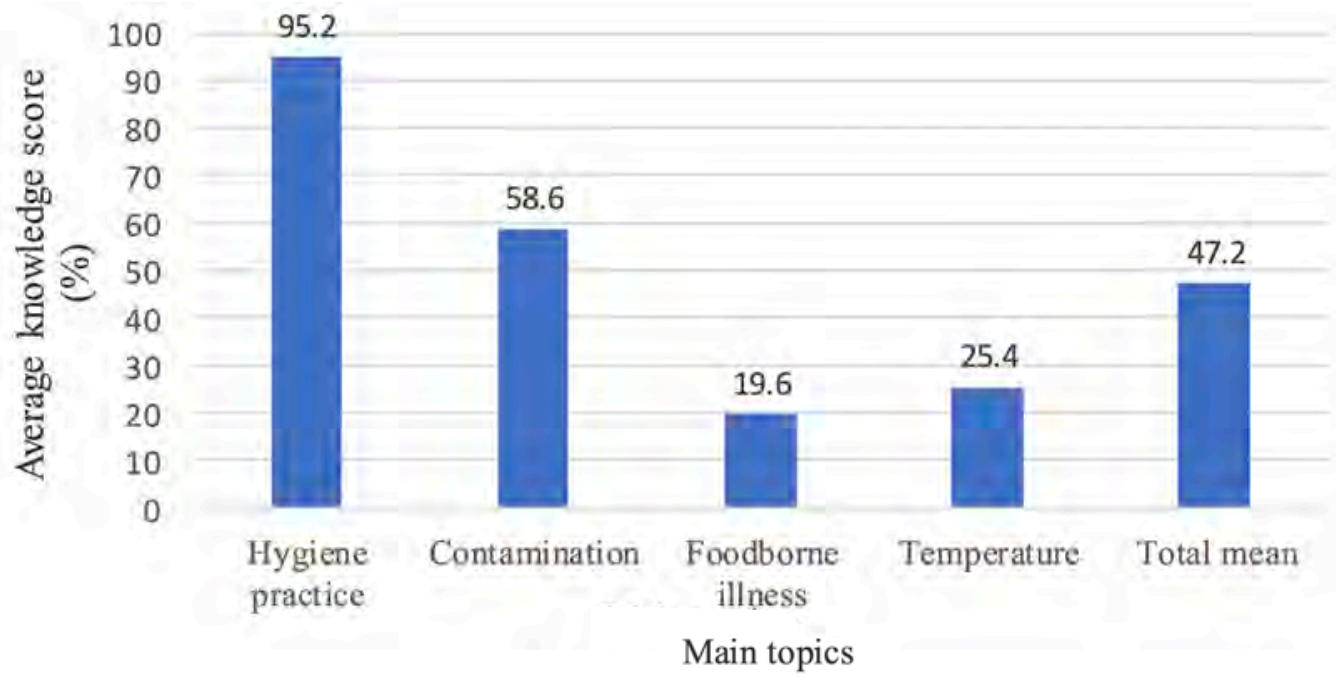

FIGURE 1. Average food safety knowledge scores of respondents based on the correct answer.

\section{Statistical analyses}

The data were analyzed using the Statistical Package for the Social Sciences version 23.0 (IBM SPSS, ver. 23, Armonk, NY). Descriptive statistics were used to determine demographic characteristics and food safety KAP of the respondents. A one-way analysis of variance test was used to compare the KAP score of participants across abattoirs. Spearman's correlation coefficient $\left(r_{s}\right)$ was used to analyze the associations in food safety KAP. Forward stepwise logistic regression yielding an adjusted odds ratio (AOR) at a $95 \%$ confidence interval (CI) and a $P$-value was used to determine the associated factors of food safety KAP. Independent variables included in the logistic regression analysis were age, employment status, level of education, experience, and food safety training. Nagelkerke's $\left(R^{2}\right)$ measure was used to evaluate the goodness of fit of the logistic regression model. Statistical significance was set at $P<0.05$.

\section{RESULTS}

Demographic characteristics of the study population ( $n$ $=422$ ) are presented in Table 1. Most respondents (94.3\%) were males and $66.1 \%$ were no older than 35 years. Reported education levels by respondents were considered low, and 49.1 and $7.3 \%$ had a primary and an informal education, respectively. Most respondents (90.3\%) had worked in an abattoir setting for 2 years or more, and $56.6 \%$ of the respondents were permanently employed by the abattoir. About $54.5 \%$ of respondents reported having past food safety training experience.

The respondents' knowledge in meat safety and their response to each item was tabulated across abattoir categories. Thus, the largest portion of respondents (63.3\%) demonstrated poor food safety knowledge (provided as supplemental material). The overall mean and standard deviation (SD) for food safety knowledge was 47.21 \pm 17.19 (of 100 possible points). Mean scores and SD for each questionnaire section were further divided into (1) knowledge of hygiene practices $(95.21 \pm 12),(2)$ knowledge of meat contamination $(58.58 \pm 28.28)$, (3) knowledge of foodborne illness (19.63 \pm 24.82$)$, and (4) knowledge of temperature (25.36 \pm 16.73 ) (Fig. 1).

The respondents' food safety knowledge score was significantly higher in Addis Ababa compared with respondents in the Dire Dawa abattoir $(P<0.0001)$. However, the respondents' knowledge score showed no significance difference between the Addis Ababa facility and the Hawassa municipal abattoir $(P>0.05)$. In addition, participants from the Hawassa municipal abattoir scored significantly higher on food safety knowledge compared with participants from the Dire Dawa abattoir $(P=0.022)$.

\section{Food safety attitudes}

The overall mean and SD for food safety attitudes was $62.24 \pm 9.50$ (of 100 possible points), demonstrating that about $46.4 \%$ of the abattoir workers had good attitudes (Table 2). About $45.7 \%$ of the participants disagreed with the statement "diarrhea does not affect my job," and 18\% of respondents indicated disagreement with the statement "meat should not be touched with a wounded hand." Most respondents $(61.6 \%)$ agreed that the use of protective clothing improves workers' safety and hygiene practices. Nearly $57 \%$ of respondents disagreed with the statement "watches, earrings, and rings can increase the risk of meat contamination." Of the respondents, $48.3 \%$ disagreed with the statement "you should not take money and touch meat with the same hand."

Approximately 49\% of respondents agreed that "safe meat handling is a meat handler job responsibility." Approximately 


\section{TABLE 2. Summary of workers' response on meat safety attitude statements at three}

abattoirs in Ethiopia, 2019 ( $n=422)$

\begin{tabular}{|c|c|c|c|c|c|}
\hline \multirow[b]{2}{*}{ Food safety statement } & \multicolumn{5}{|c|}{ No. of respondents (\%) } \\
\hline & $\begin{array}{l}\text { Strongly } \\
\text { agree }\end{array}$ & Agree & $\begin{array}{l}\text { Neither } \\
\text { agree nor } \\
\text { disagree }\end{array}$ & Disagree & $\begin{array}{l}\text { Strongly } \\
\text { disagree }\end{array}$ \\
\hline Diarrhea does not affect my job & $55(13)$ & $140(33.2)$ & $30(7.1)$ & $193(45.7)$ & $4(0.9)$ \\
\hline Work area must be clean before work starts & $23(5.5)$ & $319(75.5)$ & $42(10.0)$ & $38(9.0)$ & $0(0.0)$ \\
\hline $\begin{array}{l}\text { Mouth and nose must be covered while coughing } \\
\text { and sneezing }\end{array}$ & $29(6.9)$ & $161(38.2)$ & $77(18.2)$ & $146(34.6)$ & $9(2.1)$ \\
\hline Meat should not be touched with a wounded hand & $28(6.6)$ & $242(57.3)$ & $76(18.0)$ & $76(18.0)$ & $0(0.0)$ \\
\hline Safe meat handling is a meat handler's job responsibility & $26(6.2)$ & $206(48.8)$ & $69(16.4)$ & $117(27.7)$ & $4(0.9)$ \\
\hline It is unsafe to leave meat out of refrigeration for $>2 \mathrm{~h}$ & $17(4.0)$ & $90(21.3)$ & $54(12.8)$ & $223(52.8)$ & $38(9.0)$ \\
\hline Using a mask reduces food contamination & $22(5.2)$ & $173(41.0)$ & $70(16.6)$ & $155(36.7)$ & $2(0.5)$ \\
\hline $\begin{array}{l}\text { You should not take money and touch meat with the } \\
\text { same hand }\end{array}$ & $20(4.7)$ & $134(31.8)$ & $46(10.9)$ & $204(48.3)$ & $18(4.3)$ \\
\hline We should not smoke while working & $22(5.2)$ & $178(42.2)$ & $67(15.9)$ & $151(35.8)$ & $4(0.9)$ \\
\hline $\begin{array}{l}\text { Wood cutting boards are easier to clean than plastic } \\
\text { cutting boards }\end{array}$ & $19(4.5)$ & $235(55.7)$ & $110(26.1)$ & $54(12.8)$ & $4(0.9)$ \\
\hline $\begin{array}{l}\text { We should not rub our hands on our nose, face, hair, } \\
\text { etc., while working }\end{array}$ & $17(4.0)$ & $180(42.7)$ & $76(18.0)$ & $146(34.6)$ & $3(0.7)$ \\
\hline We should use masks at work daily & $15(3.6)$ & $230(54.5)$ & $57(13.5)$ & $117(27.7)$ & $3(0.7)$ \\
\hline We should use sanitizers to clean equipment & $17(4.0)$ & $256(60.7)$ & $64(15.2)$ & $84(19.9)$ & $1(0.2)$ \\
\hline $\begin{array}{l}\text { Watches, earrings, and rings can increase the risk of } \\
\text { meat contamination }\end{array}$ & $11(2.6)$ & $97(23.0)$ & $33(7.8)$ & $242(57.3)$ & $39(9.2)$ \\
\hline $\begin{array}{l}\text { Regular training could improve meat safety and } \\
\text { hygiene practices }\end{array}$ & $14(3.3)$ & $173(41.0)$ & $56(13.3)$ & $177(41.9)$ & $2(0.5)$ \\
\hline $\begin{array}{l}\text { Using different knives and cutting boards for muscle } \\
\text { meat and offal is a good practice }\end{array}$ & $11(2.6)$ & $169(40.0)$ & $58(13.7)$ & $179(42.4)$ & $5(1.2)$ \\
\hline $\begin{array}{l}\text { Knives and cutting boards should be properly sanitized } \\
\text { to prevent cross-contamination }\end{array}$ & $8(1.9)$ & $215(50.9)$ & $61(14.5)$ & $135(32.0)$ & $3(0.7)$ \\
\hline Improper meat storage is dangerous to health & $9(2.1)$ & $275(65.2)$ & $47(11.1)$ & $89(21.1)$ & $2(0.5)$ \\
\hline The same towel can be used to clean many places & $4(0.9)$ & $227(53.8)$ & $61(14.5)$ & $115(27.2)$ & $15(3.6)$ \\
\hline $\begin{array}{l}\text { Wearing protective clothing and shoes could help } \\
\text { improve work safety and hygienic practices }\end{array}$ & $6(1.4)$ & $260(61.6)$ & $49(11.6)$ & $105(24.9)$ & $2(0.5)$ \\
\hline Total & & 196 & $470), 02.2$ & & \\
\hline
\end{tabular}

${ }^{a}$ Proportion of respondents with good attitudes.

${ }^{b}$ Respondents' attitudes, mean score \pm SD.

$42 \%$ of respondents expressed disagreement with the statement "regular training could improve meat safety and hygienic practices." Moreover, 34.6\% of respondents disagreed with the statement "we should not rub our hands on our nose, face, hair, etc., while working." Nearly $51 \%$ of participants agreed that knives and cutting boards should be properly cleaned and sanitized. Finally, $42 \%$ of the respondents disagreed with the use of different knives and cutting boards for muscle meat and offal.

The respondents' food safety attitudes score did not show statistically significant differences between the Addis 


\section{TABLE 3. Food hygiene practice questions administered to participants and their}

responses $(n=422)$

\begin{tabular}{|c|c|c|c|c|c|}
\hline \multirow[b]{2}{*}{ Hygienic practice questions } & \multicolumn{5}{|c|}{ No. of respondents (\%) } \\
\hline & Never & Rarely & Sometimes & Often & Always \\
\hline $\begin{array}{l}\text { Do you properly clean the working space before and } \\
\text { after work? }\end{array}$ & $26(6.2)$ & $85(20.1)$ & $282(66.8)$ & $29(6.9)$ & $0(0.0)$ \\
\hline $\begin{array}{l}\text { Do you clean equipment properly before and after } \\
\text { using it? }\end{array}$ & $25(5.9)$ & $134(31.8)$ & $233(55.2)$ & $30(7.1)$ & $0(0.0)$ \\
\hline Do you clean your protective clothing properly? & $49(11.6)$ & $129(30.6)$ & $220(52.1)$ & $24(5.7)$ & $0(0.0)$ \\
\hline $\begin{array}{l}\text { Do you wash your hands after rest time when you } \\
\text { come back to work? }\end{array}$ & $393(93.1)$ & $11(2.6)$ & $17(4.0)$ & $1(0.2)$ & $0(0.0)$ \\
\hline Do you wash your hands when they become soiled? & $58(13.7)$ & $170(40.3)$ & $178(42.2)$ & $16(3.8)$ & $0(0.0)$ \\
\hline Do you wash your hands after using the toilet? & $40(9.5)$ & $195(46.2)$ & $172(40.7)$ & $15(3.6)$ & $0(0.0)$ \\
\hline Do you use gloves during work? & $387(91.7)$ & $12(2.8)$ & $21(5.0)$ & $2(0.5)$ & $0(0.0)$ \\
\hline Do you wear jewelry while working? & $380(90)$ & $31(7.3)$ & $10(2.4)$ & $1(0.2)$ & $0(0.0)$ \\
\hline Do you use a cap during work? & $82(19.4)$ & $94(22.3)$ & $160(37.9)$ & $85(20.1)$ & $1(0.2)$ \\
\hline Do you wear an apron during work? & $66(15.6)$ & $69(16.4)$ & $197(46.7)$ & $89(21.1)$ & $1(0.2)$ \\
\hline Do you eat and/or drink in the workplace? & $404(95.7)$ & $12(2.8)$ & $6(1.4)$ & $0(0.0)$ & $0(0.0)$ \\
\hline Do you smoke in your workplace? & $413(97.9)$ & $8(1.9)$ & $1(0.2)$ & $0(0.0)$ & $0(0.0)$ \\
\hline Total & \multicolumn{5}{|c|}{$256(60.7 \%),{ }^{a} 51.68 \pm 8.81^{b}$} \\
\hline
\end{tabular}

${ }^{a}$ Proportion of respondents with good practices.

${ }^{b}$ Respondents' practices, mean score $\pm \mathrm{SD}$.

Ababa facility and the Hawassa municipal abattoir $(P>$ 0.05). Participants from the Addis Ababa abattoir recorded a significantly higher food safety attitudes score compared with those from the Dire Dawa abattoir $(P<0.0001)$. Similarly, participants in the Hawassa and Dire Dawa municipal abattoirs showed significant differences in their food safety attitudes scores $(P=0.004)$.

\section{Hygienic practices}

The overall mean and SD for the food safety practices category was $51.68 \pm 8.18$ (of 100 possible points) (Table 3 ). Approximately $61 \%$ of respondents were shown to have good hygienic practices. However, this study indicated that $66.8 \%$ of the respondents sometimes clean the working space before and after work. Slightly more than half (52\%) of the participants replied that sometimes they clean their protective clothes. Some participants never washed their hands after resting (93.1\%), when they become soiled (13.7\%), or after using the toilet (9.5\%). Furthermore, most respondents $(91.7 \%)$ indicated that they never use gloves during work. Ninety percent of the participants never wear jewelry, and $19.4 \%$ never use a cap, whereas $15.6 \%$ never wear an apron during work. More than $95 \%$ of the respondents claimed that they never eat, drink, and smoke in the workplace.

The food safety practices score of respondents showed no significant difference between the Addis Ababa facility and the Hawassa municipal abattoir $(P>0.05)$. The food safety practices score of respondents from the Addis Ababa abattoir was significantly higher than that of participants in the Dire Dawa abattoir $(P<0.0001)$. Similarly, the food safety practices score of participants from the Hawassa municipal abattoir was significantly higher compared with that of participants from the Dire Dawa abattoir $(P<0.0001)$.

A significant positive correlation was observed between food safety knowledge and practices $\left(r_{s}=0.569, P<\right.$ $0.0001)$, knowledge and attitudes $\left(r_{s}=0.735, P<0.0001\right)$, and practices and attitudes $\left(r_{s}=0.518, P<0.0001\right)$. The regression analysis showed that respondents with primary school education $(\mathrm{AOR}=28.93,95 \% \mathrm{CI}=16.14$ to 51.85$)$ and informal education $(\mathrm{AOR}=39.95,95 \% \mathrm{CI}=9.19$ to 173.70) were more likely to have poor knowledge compared with the group that had an education level of high school and above $(P<0.0001$; Table 4$)$. 


\section{TABLE 4. Association of knowledge, attitudes, and practices of respondents and their sociodemographic characteristics ( $n=422$ )}

\begin{tabular}{|c|c|c|c|c|c|}
\hline Variables & Predictors & Category & $\operatorname{AOR}(95 \% \mathrm{CI})$ & $P$-value & $\begin{array}{c}\text { Nagelkerke } \\
\left(R^{2}\right)\end{array}$ \\
\hline \multirow{3}{*}{ Knowledge $^{a}$} & \multirow{3}{*}{ Education level } & Secondary education and above & 1 & & \\
\hline & & Primary school education & $28.93(16.14-51.85)$ & 0.000 & 0.525 \\
\hline & & Informal education & $39.95(9.19-173.70)$ & 0.000 & \\
\hline \multirow{6}{*}{ Attitude $^{b}$} & \multirow{3}{*}{ Education level } & Secondary education and above & 1 & & \\
\hline & & Primary school education & $13.28(1.728-101.97)$ & 0.013 & 0.206 \\
\hline & & Informal education & $74.86(9.05-619.22)$ & 0.000 & \\
\hline & \multirow{3}{*}{ Education level } & Secondary education and above & 1 & & \\
\hline & & Primary school education & $1.45(0.78-2.66)$ & 0.238 & \\
\hline & & Informal education & $7.88(2.56-24.25)$ & 0.000 & \\
\hline \multirow{7}{*}{ Practice $^{c}$} & \multirow{2}{*}{ Work experience } & $\geq 2$ years & 1 & & 0.356 \\
\hline & & $<2$ years & $2.50(1.132-5.51)$ & 0.023 & \\
\hline & \multirow{3}{*}{ Employment status } & Permanent & 1 & & \\
\hline & & Contract & $10.86(5.09-23.17)$ & 0.000 & \\
\hline & & Daily & $1.57(0.90-2.71)$ & 0.111 & \\
\hline & \multirow{2}{*}{ Knowledge } & Good knowledge & 1 & & \\
\hline & & Poor knowledge & $3.07(1.59-5.95)$ & 0.001 & \\
\hline
\end{tabular}

${ }^{a}$ Variables entered: age, employment status, education level, experience, food safety training, and attitude.

${ }^{b}$ Variables entered: age, employment status, education level, experience, food safety training, and knowledge.

${ }^{c}$ Variables entered: age, employment status, education level, experience, food safety training, knowledge, and attitude.

The respondents with primary school education $(\mathrm{AOR}=$ $13.28,95 \% \mathrm{CI}=1.728$ to $101.97, P=0.013)$ and informal education $(\mathrm{AOR}=74.86,95 \% \mathrm{CI}=9.05$ to $619.22, P<$ 0.0001 ) were more likely to have poor attitudes toward food safety. Respondents with informal education $(\mathrm{AOR}=7.88$, $95 \% \mathrm{CI}=2.56$ to 24.25 ) and contract employee status (AOR $=10.86,95 \% \mathrm{CI}=5.09$ to 23.17 ) were more likely to have poor food safety practices $(P<0.0001)$. Respondents with less than 2 years of work experience $(\mathrm{AOR}=2.50,95 \% \mathrm{CI}=$ 1.132 to $5.51, P=0.023)$ and poor knowledge $(\mathrm{AOR}=3.07$, $95 \% \mathrm{CI}=1.59$ to $5.95, P=0.001)$ were more likely to have poor food safety practices (Table 4 ).

\section{DISCUSSION}

The study reveals that approximately $56 \%$ of the respondents had a low level of education. This is in accordance with the study by Matchawe et al. (27) that showed that most abattoir workers in Cameroon had low levels of education. This low level of education might negatively affect food safety, because workers in food processing with a lower education level may be less likely to follow safe food handling procedures (14). Generally, the abattoir workers in this study demonstrated poor food safety knowledge. The lowest score within the knowledge category was observed for foodborne illness, with mean score of 19.63. Similarly, a lack of food handler knowledge on foodborne pathogens and associated illnesses was reported in Kuwait and Portugal $(3,20)$. A lack of knowledge related to foodborne illness might correlate with the respondents' low educational status and lack of appropriate on-the-job food safety training.

In addition, the participants demonstrated poor understanding about the benefits of sterilization and the general effect of temperature on microorganisms and bacterial pathogens. This result corroborates with the work of Bas et al. (9), which indicated that food handlers in Turkey scored the lowest in knowledge about critical storage temperature. The consequences of such a knowledge gap may increase microbial growth on surfaces, meat, and meat products, leading to spoilage and potential foodborne disease outbreaks. Moreover, poor understanding of the effect of temperature on microorganisms and bacterial pathogens could be a major hindrance for effective implementation of hazard analysis critical control point of the production process (39). 
About $54.5 \%$ of respondents had taken food safety training. However, training had no influence $(P>0.05)$ on the food safety knowledge status of the respondents. This finding contradicts with the report of Bas et al. (9), which indicated that trained food handlers had a significantly higher knowledge score compared with untrained food handlers. Thus, the efficacy of current food safety training is uncertain, because some document files (the training package) of the abattoirs indicated that trainings mainly focused on the art of slaughtering, stunning, splitting, and hide removing. Hence, there is a need to incorporate appropriate food safety training in the package as an effective food safety management strategy.

About $45.7 \%$ of the respondents had a disagreement about the statement "diarrhea does not affect my job." Such attitudes may lead to risky practices such as touching meat while presenting active sickness, potentially leading to contamination with bacterial and viral pathogens frequently involved in foodborne outbreaks (5). In addition, $48.3 \%$ of the respondents disagreed with the statement "you should not take money and touch meat with the same hand." This attitude is concerning, because different studies have indicated that physical money can act as a vehicle of crosscontamination and simultaneous handling of food and physical money could result in foodborne infections $(8,19)$.

Approximately $42 \%$ of respondents disagreed about the use of regular training to improve meat safety and hygienic practice. The participants did not seem to value the role of training. As highlighted by Seaman (35), training may be perceived as a waste of time for the food handlers. This issue highlights the need for creative and interactive training programs to improve meat safety and hygienic practices of the workers. As stated by Todd et al. (38), during various daily activities at work, hands quickly become contaminated from various sources and can contaminate meat. However, the findings of this study indicated that approximately (35\%) of respondents had a disagreement with the statement "we should not rub our hands on our nose, face, hair, etc., while working."

This study identified poor hygiene practices. About $66.8 \%$ of the participants responded that they clean the working space before and after work only sometimes. In contrast, a report by Abdul-Mutalib et al. (1) indicated good practices of food handlers on hand washing and cleaning of the working area. Poor hygiene practices require attention, because Alhaji and Baiwa (4) identified that cleaning of equipment and surfaces as the most preventive hygienic practice in meat processing. This study also revealed that $52 \%$ of the participants claimed they sometimes clean their protective clothes. The same practice was reported in slaughtering houses of South Africa (30).

The participants' practice of wearing protective clothing was not satisfactory. The personal protective clothing supply and their cost might be limiting factors, because the selected abattoirs are owned by the federal government and are nonprofitable service provider enterprises; thus, there is a budget limitation to fulfill the personal protective equipment requirement for all workers. Similarly, a study conducted in Kenya by Cook et al. (15) reported that the cost of protective clothing is the limiting factor and less than $50 \%$ of workers wore protective equipment at all times. In this study, most participants claimed that they never eat, drink, and smoke in the workplace. Such practices were common in reports of a similar study in Iran meat processing plants (6).

Analyzing the associations in KAP, a significant positive correlation was observed $(P<0.0001)$ that indicates that the food safety knowledge level of abattoir workers possibly influences their attitudes and practices in meat safety. These findings are supported by Al-Kandari et al. (3), who demonstrated a significantly positive correlation among the three variables. The respondents with primary school and informal education were more likely to have poor knowledge compared with those who had a higher level of education $(P<0.0001)$. This is in agreement with the study by Lee et al. (26) that showed education level had different degrees of impact on food safety knowledge.

The respondents with primary school education $(P=$ $0.013)$ and informal education $(P<0.0001)$ were more likely to have poor attitudes toward food safety. However, these findings contradict a report that indicated that respondents with higher educational levels do not necessarily have good attitudes (1). Finally, respondents with poor knowledge $(P=0.001)$ were more likely to have poor practices. These findings agreed with evidence from Italy that showed having good knowledge leads to good practices (5).

The limitations of this study include (1) data were based on self-response, (2) model and behavioral theory were not used to explain food safety KAP, and (3) the study only focused on three selected abattoirs in Ethiopia; thus, results should not be generalized to the nation and other abattoirs.

The findings of this study demonstrated that respondents had generally poor KAP toward meat safety. Specially, most workers were identified as having poor knowledge about foodborne illness and meat storage temperature. Therefore, the following are recommended: (1) development of training modules focusing on food safety KAP for abattoir workers and (2) creation of a training-of-the-trainer program, including topics such as personal hygiene, meat safety, sanitation, and temperature management, for abattoir workers and managers.

\section{ACKNOWLEDGMENTS}

The authors acknowledge data collectors, study participants, and abattoir administrators for their unreserved contributions to the success of this study. This work was funded by the U.S. Agency for International Development (USAID) Bureau for Food Security under Agreement AID-OAA-L-15-00003 as part of the Feed the Future Innovation Lab for Livestock Systems. Any opinions, findings, conclusions, or recommendations expressed here are those of the authors alone. 


\section{REFERENCES}

1. Abdul-Mutalib, N., M. Abdul-Rashid, S. Mustafa, S. Amin-Nordin, R. A. Hamat, and M. Osman. 2012. Knowledge, attitude and practices regarding food hygiene and sanitation of food handlers in Kuala Pilah, Malaysia. Food Control 27:289-293.

2. Agüeria, D. A., C. Terni, V. M. Baldovino, and D. Civit. 2018. Food safety knowledge, practices and attitudes of fishery workers in Mar del Plata, Argentina. Food Control 91:5-511.

3. Al-Kandari, D., J. Al-abdeen, and J. Sidhu. 2019. Food safety knowledge, attitudes and practices of food handlers in restaurants in Kuwait. Food Control 103:103-110.

4. Alhaji, N. B., and M. Baiwa. 2015. Factor affecting workers' delivery of good hygienic and sanitary operations in slaughterhouses in northcentral Nigeria. Sokoto J. Vet. Sci. 13:29-37.

5. Angelillo, I. F., M. R. Foresta, C. Scozzafava, and M. Pavia. 2001. Consumers and foodborne diseases: knowledge, attitudes and reported behavior in one region of Italy. Int. J. Food Microbiol. 64:161-166.

6. Ansari-Lari, M., S. Soodbakhsh, and L. Lakzadeh. 2010. Knowledge, attitudes and practices of workers on food hygienic practices in meat processing plants in Fars, Iran. Food Control 21:260-263.

7. Azanaw, J., M. Gebrehiwot, and H. Dagne. 2019. Factors associated with food safety practices among food handlers: facility-based cross-sectional study. BMC Res. Notes 12:683.

8. Barolia, S. K., S. Verma, and B. K. Verma. 2011. Coliform contamination on different paper currency in Ajmer, Rajasthan, India. Uni. J. Environ. Res. Tech. 1:552-556.

9. Bas, M., A. S. Ersun, and G. Kivanc. 2006. The evaluation of food hygiene knowledge, attitudes, and practices of food handlers in food businesses in Turkey. Food Control 17:317-322.

10. Bekele, T., G. Zewde, G. Tefera, A. Feleke, and K. Zerom. 2014. Escherichia coli O157:H7 in raw meat in Addis Ababa, Ethiopia: Prevalence at an abattoir and retailers and antimicrobial susceptibility. Int. J. Food Contamin. 1:4.

11. Beyi, A. F., A. T. Fite, E. Tora, A. Tafese, T. Genu, T. Kaba, T. J. Beyene, T. Beyene, M. G. Korsa, F. Tadesse, L. D. Zutter, B. M. Goddeeris, and E. Cox. 2017. Prevalence and antimicrobial susceptibility of Escherichia coli $\mathrm{O} 157$ in beef at butcher shops and restaurants in central Ethiopia. BMC Microbiol. 17:49.

12. Bouwknegt, M., M. J. Mangen, I. H. M. Friesema, W. Pelt, and A. H. Havelaar. 2014. Disease burden of food-related pathogens in the Netherlands, 2012. RIVM letter report 2014-0069.

13. Chekol, F. A., M. F. Melak, A. K. Belew, and E. G. Zeleke. 2019. Food handling practice and associated factors among food handlers in public food establishments, Northwest Ethiopia. BMC Res. Notes 12:20.

14. Clayton, D. A., C. J. Griffith, P. Price, and A. C. Peters. 2002. Food handlers' beliefs and self-reported practices. Int. J. Environ. Health Res. 12:25-39.
15. Cook, E. A. J., W. A. de Glanville, L. F. Thomas, S. Kariuki, B. M. de C. Bronsvoort, and E. M. Fèvre. 2017. Working conditions and public health risks in slaughterhouses in western Kenya. BMC Public Health 17:14.

16. Curtis, V., and S. Cairncross. 2003. Effect of washing hands with soap on diarrhoea risk in the community: a systematic review. Lancet Infect. Dis. 23:275-281.

17. Dadi, L., and D. Asrat. 2008. Prevalence and antimicrobial susceptibility profiles of thermotolerant Campylobacter strains in retail raw meat products in Ethiopia. Ethiop. J. Health Dev. 22:195-200.

18. European Food Safety Authority and European Centre for Disease Prevention and Control. 2016. The European Union summary report on trends and sources of zoonoses, zoonotic agents and foodborne outbreaks in 2015. EFSA J. 14:4634.

19. Girma, G., T. Ketema, and K. Bacha. 2014. Microbial load and safety of paper currencies from some food vendors in Jimma Town, Southwest Ethiopia. BMC Res. Notes 7:843.

20. Gomes-Neves, E., A. C. Araújo, E. Ramos, and C. S. Cardoso. 2007. Food handling Comparative analysis of general knowledge and practice in three relevant groups in Portugal. Food Control 18:707-712.

21. Grace, D. 2015. Food safety in low and middle income countries. Int. J. Environ. Res. Publ. Health 12:10490-10507.

22. Haileselassie, M., H. Taddele, K. Adhana, and S. Kalayou. 2013. Food safety knowledge and practices of abattoir and butchery shops and the microbial profile of meat in Mekelle City, Ethiopia. Asian Pac. J. Trop. Biomed. 3:407-412.

23. Havelaar, A. H., A. V. Galindo, D. Kurowicka, and R. M. Cooke. 2008. Attribution of foodborne pathogens using structured expert elicitation. Foodborne Pathog. Dis. 5:649-659.

24. Havelaar, A. H., M. D. Kirk, P. R. Torgerson, H. J. Gibb, T. Hald, R. J. Lake, N. Praet, D. C. Bellinger, N. R. de Silva, N. Gargouri, N. Speybroeck, A. Cawthorne, C. Mathers, C. Stein, F. J. Angulo, and B. Devleesschauwer. 2015. World Health Organization global estimates and regional comparisons of the burden of foodborne disease in 2010. PLoS Med. 12:e1001923.

25. Hoffmann, S., P. Fischbeck, A. Krupnick, and M. McWilliams. 2007. Using expert elicitation to link foodborne illnesses in the United States to foods. J. Food Prot. 70:1220-1229.

26. Lee, H. K., H. A. Halim, K. L. Thong, and L. C. Chai. 2017. Assessment of food safety knowledge, attitude, self-reported practices, and microbiological hand hygiene of food handlers. Int. J. Environ. Res. Publ. Health 14:55.

27. Matchawe, C., L. M. Ndip, A. Zuliani, J. T. Tsafack, B. J. Nsawir, E. Piasentier, and N. Joseph. 2019. Knowledge, attitude and practices (KAP) regarding meat safety and sanitation among carcass handlers operating at the Yaoundé slaughterhouse, Cameroon. Int. J. Adv. Res. Publ. 3:150-155.
28. Molla, B., and A. Mesfin. 2003. A survey of Salmonella contamination in chicken carcass and giblets in central Ethiopia. Revue Méd. Vét. 154:267-270.

29. Molla, B., R. Yilma, and D. Alemayehu. 2004. Listeria monocytogenes and other Listeria spp. in retail meat and milk products in Addis Ababa, Ethiopia. Ethiop. J. Health Dev. 18:208-212.

30. Nyamakwere, F., V. Muchenje, B. Mushonga, E. Kandiwa, M. Makepe, and G. Mutero. 2017. Evaluation of meat safety knowledge, attitudes and practices among slaughterhouse workers of Amathole district in eastern Cape Province, South Africa. J. Food Saf. Hyg. 3:7-15.

31. Nyamakwere, F., V. Muchenje, B. Mushonga, M. Makepe, and G. Mutero. 2016. Assessment of Salmonella, Escherichia coli, Enterobacteriaceae and aerobic colony counts contamination levels during the beef slaughter process. J. Food Saf. 36:548-556.

32. Painter, J. A., R. M. Hoekstra, T. Ayers, R. V. Tauxe, C. R. Braden, F. J. Angulo, and P. M. Griffin. 2013. Attribution of foodborne illnesses, hospitalizations, and deaths to food commodities by using outbreak. J. Emerg. Infect. Dis. 19:407-415.

33. Sang, X. L., X. C. Liang, Y. Chen, J. D. Li, J. G. Li, L. Bai, and J. Y. Sun. 2014. Estimating the burden of acute gastrointestinal illness in the community in Gansu Province, northwest China, 2012-2013. BMC Publ. Health 14:787.

34. Satheesh, N., M. Temeche, and K. Dibaba. 2016. Food safety knowledge, practice and attitude of food handlers in traditional hotels of Jimma town, southern Ethiopia. Annals Food Sci. Technol. 17:507-517.

35. Seaman, P. 2010. Food hygiene training: introducing the food hygiene training model. Food Control 21:381-387.

36. Seleshe, S., C. Jo, and M. Lee. 2014. Meat consumption culture in Ethiopia. Korean. J. Food Sci. Animal Res. 34:7-13.

37. Tegegne, H. A., and H. W. W. Phyo. 2017. Food safety knowledge, attitude and practices of meat handler in abattoir and retail meat shops of Jigjiga town, Ethiopia. J. Prev. Med. Hyg. 58:E320-E327.

38. Todd, E. C. D., B. S. Michaels, D. Smith, J. D. Greig, and C. A. Bartleson. 2010. Outbreaks where food workers have been implicated in the spread of foodborne disease. Part 9. Washing and drying of hands to reduce microbial contamination. J. Food Prot. 73:1937-1955.

39. Walker, E., C. Pritchard, and S. Forsythe. 2003. Food handlers' hygiene knowledge in small food businesses. Food Control 14:339-343.

40. Yenealem, D. G., W. W. Yallew, and S. Abdulmajid. 2020. Food safety practice and associated factors among meat handlers in Gondar town: a cross-sectional study. J. Environ. Publ. Health 2020:7421745. 